\title{
Publishing a Master's Thesis: A Guide for Novice Authors
}

\author{
Robert G. Resta • Patricia McCarthy Veach • \\ Sarah Charles • Kristen Vogel • Terri Blase • \\ Christina G. S. Palmer
}

Received: 27 January 2009 / Accepted: 23 November 2009/Published online: 14 January 2010

(C) The Author(s) 2010. This article is published with open access at Springerlink.com

\begin{abstract}
Publication of original research, clinical experiences, and critical reviews of literature are vital to the growth of the genetic counseling field, delivery of genetic counseling services, and professional development of genetic counselors. Busy clinical schedules, lack of time and funding, and training that emphasizes clinical skills over research skills may make it difficult for new genetic counselors to turn their thesis projects into publications. This paper summarizes and elaborates upon a presentation aimed at de-mystifying the publishing process given at the 2008 National Society of Genetic Counselors Annual Education Conference. Specific topics include familiarizing prospective authors, particularly genetic counseling students, with the basics of the publication process and related ethical considerations. Former students' experiences with publishing master's theses also are described in hopes of encouraging new genetic counselors to submit for publication papers based on their thesis projects.
\end{abstract}

R. G. Resta

Swedish Cancer Institute, Swedish Medical Center,

Seattle, WA, USA

P. McCarthy Veach

Department of Educational Psychology,

University of Minnesota,

Minneapolis, MN, USA

S. Charles

Jefferson Kimmel Cancer Center,

Thomas Jefferson University Hospital,

Philadelphia, PA, USA

K. Vogel

Center for Medical Genetics,

NorthShore University HealthSystem,

Evanston, IL, USA
Keywords Professionalization · Publishing · Journal writing · Genetic counseling · Publication ethics · Master's thesis · Graduate training

\section{Introduction}

Scholarship is important for growth of a profession and for clinical care. For these reasons, the American Board of Genetic Counseling (ABGC) endorses scholarly activities through Practice Based Competency IV.5 (American Board of Genetic Counseling 2009). Boyer (1990) describes four types of scholarship (Scholarship of Discovery, Scholarship of Integration, Scholarship of Application, and Scholarship of Teaching), all of which are endorsed by ABGC and required of accredited genetic counseling training programs. The first three types of scholarship, which involve generating new knowledge or applying existing knowledge

T. Blase

Department of Maternal Fetal Medicine,

Advocate Christ Medical Center,

Oak Lawn, IL, USA

C. G. S. Palmer

Department of Psychiatry \& Biobehavioral Sciences, UCLA,

Los Angeles, CA, USA

C. G. S. Palmer

Department of Human Genetics, UCLA,

Los Angeles, CA, USA

C. G. S. Palmer $(\bowtie)$

UCLA Semel Institute,

760 Westwood Plaza, Room 47-422,

Los Angeles, CA 90095, USA

e-mail: cpalmer@mednet.ucla.edu 
to an important problem, are the basis of the ABGC's requirement that students in accredited programs engage in scholarship and complete a scholarly product. The ABGC defines a scholarly product to include: a master's thesis, an independent research project, a literature review/case report, a formal needs assessment, design and implementation of an innovative patient, professional, or community educational program, and/or preparation of a grant proposal.

The purpose of this article is to encourage students to disseminate their scholarly work (except grant proposals) through a journal publication. This article was developed from an Educational Breakout Session (EBS) at the 2008 National Society of Genetic Counselors (NSGC) Annual Education Conference and draws upon the experiences of a past editor and current assistant editor of the Journal of Genetic Counseling (JOGC), a student mentor, and recent genetic counseling graduates who successfully turned their student thesis projects into peer-reviewed publications.

Engaging in scholarship is important for increasing genetic counselors' self-knowledge, but dissemination of scholarship is essential for the growth of the genetic counseling field. McGaghie and Webster (2009) identify a wide range of types of scholarly products that promote broad dissemination of information, including peerreviewed journal articles (e.g., original research, case reports, review articles), book chapters, books or monographs, edited books, essays, editorials, book reviews, letters, conference reports, educational materials, reports of teaching practices, curriculum description, videos, simulations, simulators, and web-based tutorials. As evidence of the importance of disseminating scholarship to the field of genetic counseling, dissemination of scholarly products is actively promoted by the NSGC, the major professional organization for the genetic counseling profession. A prominent example of NSGC's commitment to dissemination is the $J O G C$, a professional journal devoted to disseminating peer-reviewed information relevant to the practice of genetic counseling. The success of this journal over nearly two decades is a strong indicator of the value genetic counselors place on publishing journal articles as an essential product of scholarship.

Individuals who have completed a master's thesis or equivalent should consider publication. This "call to publish" student work is based on evidence that a large proportion of students engage in a scholarly activity with publication potential. A recent survey of 531 genetic counselors suggests that $75 \%$ of respondents fulfilled their scholarly activity requirement via a master's thesis (Clark et al. 2006). Among this group, $21 \%$ classified their thesis as "hypothesis driven" and $20 \%$ classified it as a "descriptive study." Although the research may be relatively small scale given the time and resource constraints of short training programs ( $\leq 2$ years), it nonetheless offers a rich and varied source of information about the practice of genetic counseling that could be shared with the broader community through publication. Yet Clark et al. (2006) found that only $21.6 \%$ of respondents who completed a master's thesis had submitted a manuscript for publication in a peerreviewed journal. It appears that many students do not submit their research for professional publication, perhaps due to a combination of time constraints, lack of mentoring and support, unfamiliarity with the publication process, lack of professional confidence, and fear of rejection (Clark et al. 2006; Cohen et al. 2008; Driscoll and Driscoll 2002; Keen 2006). Because this is one aspect of scholarship that has received limited attention, guidance regarding the details and vicissitudes of the publication process, and acknowledgement that master's theses can be successfully published, are needed.

Of course, one might question why students should or would publish the results of their graduate work. The answer is complex, without a "one size fits all," because scholarship can be intrinsically and/or extrinsically motivated. McGaghie and Webster (2009) describe intrinsic motives as including sharing knowledge, career advancement, status improvement, collegial approval, personal pleasure, and response to challenge; extrinsic motives include academic pressure, commitment to patient care, practice improvement, and promoting the use of new technologies. Although the reasons genetic counselors publish articles have not been empirically evaluated, Clark et al. (2006) (i) concluded that a substantial number of genetic counselors consider active involvement in research (a form of scholarship and precursor to publication) to be a core role, and (ii) found that respondents endorsed a range of intrinsic and extrinsic motives for their involvement in research. These reasons included interest in the subject, contributing to the field, personal development/satisfaction, diversifying job responsibilities, job requirements, lack of existing research on a particular topic, and career advancement. It is reasonable to infer that these reasons would extend to publication as well.

The work that culminates in a master's thesis provides the basis for a professional journal article. However, writing a professional journal article differs from writing a master's thesis. This article, therefore, provides practical ideas and considerations about the process for developing a master's thesis into a peer-reviewed journal article and describes successful case examples. Research and publication occur in stages and include many important topics. Previous genetic counseling professional development articles have partially or comprehensively addressed the topics of developing and conducting a research project (Beeson 1997), writing a manuscript (Bowen 2003), and the peerreview process (Weil 2004). This paper expands on previous articles by describing the publication process and 
discussing publication ethics, with emphasis on aspects pertinent to publishing a master's thesis. It is hoped that this article will encourage genetic counselors to publish their research.

The primary audience for this article is genetic counselors who are conducting a master's thesis or equivalent or who completed a thesis in the last few years which remains unpublished. The secondary audience is other novice authors and affiliated faculty of genetic counseling training programs. Although the focus of this paper is on journal publications which are subject to a peer-review process (e.g., original research, clinical reports, and reviews), some of the basic information applies to a variety of publishing forms.

\section{The Publication Process}

\section{Publish Before It Perishes}

Like produce and dairy products, data have a limited shelf life. Research results may be rendered marginal by new research, social changes, and shifts in research trends. For example, a study of patient reluctance to undergo genetic testing due to concerns about health insurance discrimination conducted in December 2007 would have been obsolete when the Genetic Information Nondiscrimination Act (Pub.L. 110-233, 122 Stat. 881, enacted May 21, 2008) was enacted 5 months later. Or studies of whether patients think they might undergo testing if a gene for a particular condition were identified become less relevant once the gene is actually mapped and sequenced.

The hardest part about writing is actually writing. Making the time to sit down and compose a report of research findings is a very difficult first step. As noted in the three case examples, this is particularly true for a recent graduate whose time is occupied with searching for a new job, moving to a new city, and learning the details of a new job. However, the longer you wait, the more difficult it becomes, and the greater the risk that your data will grow stale. If you do not write it, the paper will likely not get written. The three case examples identify strong mentorship, ongoing communication with co-authors, constructive criticism, and commitment to publication by every author as key elements for successfully preparing a manuscript. The following sections describe basic processes for preparing a paper. See also Table 1 for helpful references about technical aspects of manuscript preparation.

\section{Choosing a Journal}

Research delivered to an inappropriate audience is ignored. Many journals publish genetic counseling research-as demonstrated by the three case examples - and therefore, choosing the right journal is critical (Thompson 2007). The first step is to decide who the audience should be. Is it important to reach genetic counselors? Medical geneticists? Or is the audience outside of the genetic counseling community? Some genetic counseling research is of interest to researchers in patient education, decision-making, or the social sciences. Clinicians such as surgeons, radiology technicians, psychologists, and family practice physicians might benefit from a greater understanding of genetic counseling and how it interfaces with their specialties.

The next step is to decide whether the journal is interested in the type of research conducted. For example, does the journal publish articles mostly on medical and clinical issues? Does it publish qualitative research? A description of the scope, aims, and types of research that are published is located in the "Instructions to Contributors" section on the web page of most journals. A look at the journal's editorial board might also provide a good idea of a journal's theoretical approaches, philosophical orientation, and research interests. Another strategy is to contact the journal's editor or a member of the editorial board prior to submitting a

Table 1 Selected Resources For Manuscript Preparation

Bowen, N. (2003) How to write a research article for the Journal of Genetic Counseling. Journal of Genetic Counseling, 12: 5-21.

Day, R., \& Gastel, B. (2006). How to write and publish a scientific paper, 6th ed. Westport, CT: Greenwood Press.

Huth, E. J. (1999). Writing and publishing in medicine, 3rd ed. Baltimore: Williams and Wilkins.

International Committee of Medical Journal Editors. (2008). Uniform requirements for manuscripts submitted to biomedical journals: Writing and editing for biomedical publication. www.icmje.org Accessed 1/14/2009.

Iverson, C., \& Christiansen, S., Flanagin, A. (2007). AMA manual of style: a guide for authors and editors, 10th ed. New York, NY: Oxford University Press.

Lang, T., \& Secic, M. (2006). How to report statistics in medicine: annotated guidelines for authors, editors, and reviewers, 2 nd ed. Philadelphia: American College of Physicians.

Sutcliffe, A. (1994). The New York public library writer's guide to style and usage. New York, NY: Stonesong Press/HarperCollins Publishers. Style Manual Committee - Council of Science Editors. (2006). Science, style, and format: The CSE manual for authors, editors, and publishers. 7th Edition. Reston, VA: The Rockefeller Univ. Press.

University of Chicago Press (Staff). (2003). Chicago manual of style, 23rd ed. Chicago: Univ. of Chicago Press. 
manuscript to discuss the appropriateness of the manuscript for the journal. Many editors welcome such pre-submission contact since it reduces their workload of reading inappropriate manuscripts.

A journal's "impact factor" may be important to some authors when considering where to publish a manuscript. The impact factor is a-perhaps imperfect - statistical measure of a journal's importance. The impact factor was developed in the early 1960s by Eugene Garfield and Irving Sher and is technically defined as $\mathrm{A} / \mathrm{B}$, where $\mathrm{A}=$ the number of times articles published in that journal were cited and $\mathrm{B}=$ the number of citable articles published by the journal (letters and editorials are not usually citable articles) (Garfield 1994). An impact factor of one indicates that on average, articles published in the journal were cited once by other authors.

A journal's impact factor can vary greatly from year to year, and its practical utility is widely debated (Andersen et al. 2006; Chew et al. 2006; Greenwood 2007; Ha et al. 2006; The PLoS Medicine Editors 2006). Genetic counselors often publish small studies and case reports. The journals that might publish such papers usually have impact factors of ten or less. Thus the impact factor may be a less important consideration for many genetic counselors when deciding where to publish.

A publisher's copyright policy may also influence the choice of where to publish. The majority of publishers own the copyright (United States Copyright Office 2008) and authors do not have the right to copy, re-use, or distribute their own publications without buying reprints, which can be a significant source of income for publishers. Some journals, like the Public Library of Science (PLoS), are completely Open Access and make all articles fully available online. Other journals have Delayed Open Access, which makes articles publicly available after a specified period of time, often a year or two. Many journals, such as the $J O G C$, promote Hybrid Open Access in which authors, for a fee, can make their articles publicly available. Some journals will make select articles publicly available, usually those that attract media attention. For grant-funded research, consider the requirements of the funding source; some granting agencies require that the research results be made publicly available at some point.

\section{Peer Review}

Peer review is the process in which two or three experts evaluate a manuscript to determine whether it is worthy of publication. Peer review is the backbone of scholarly publishing; no research manuscript gets published until a team of reviewers and journal editors vets it. Ideally, reviewers are objective, constructively critical, openminded, fair, and insightful. Some journals blind the reviewer to the author's identity, in hopes that the authors' reputations or professional relationships will not influence the review. Some journals will let authors suggest reviewers or request that certain people not review a manuscript. A journal's peer review policies may be another important consideration in choosing where to submit a manuscript.

In practice, peer review is not always ideal (Benose et al. 2007; Curfman et al. 2008; Hames 2007; Wager et al. 2006). Nonetheless, no better or viable alternative has been proposed. Reviews may sometimes appear to be arbitrary, unfair, and poorly performed. Reading such reviews can be very difficult and frustrating, even for experienced authors. However, it is a reviewer's job to be critical, and there may be elements of truth in even the most negative reviews. Some editors may be willing to send a manuscript to another reviewer if an original reviewer produces a harshly critical or poorly thought out critique. Some journals have a formal appeals process if a manuscript is rejected or an author feels a review is inaccurate, inappropriate, or biased. However, sometimes it is simply easier to submit the manuscript to a different journal. Case \# 2 describes a successful example where submitting a manuscript to a different journal led to publication.

The manuscript rejection rate varies widely across journals, but about half of all manuscripts are rejected or require significant revisions (Armstrong et al. 2008; Hall and Wilcox 2007; Liesegang et al. 2007). About half of rejected manuscripts are published in other journals (Armstrong et al. 2008; Hall and Wilcox 2007; Liesegang et al. 2007). Even among articles that are accepted for publication, the vast majority will require significant revisions. All three case examples describe manuscripts that underwent significant revision. Thus, prospective authors should not be disheartened if a manuscript is rejected or needs extensive re-writing; this is the rule rather than the exception. Many editors are willing to work with authors who have questions about specific comments or how best to incorporate the reviewers' suggestions. Busy journal editors would rather answer questions up front than have to laboriously edit a revised manuscript and send it back for further revisions.

Peer review, and the subsequent manuscript revisions, along with the number of manuscripts submitted to the journal, are probably the most critical bottlenecks in determining how long it takes before a manuscript appears in print. Typically, a year or more may pass from the time of submission to the publication date. The three case examples include their timeframes to highlight the need for perseverance and patience with the publication process.

The clearest way for authors to respond to editors' and reviewers' comments is to prepare a table that lists each comment and how the authors addressed them, item by item. Some reviewers' comments may be inaccurate or simply unrealistic (e.g. "The authors should re-do the entire research study..."); these can be discussed in the table or in the cover 
letter that accompanies the table. Additional information about the peer-review process can be found in Weil (2004).

\section{Acceptance!}

Once a manuscript is accepted for publication, the publisher or the journal editor will send a copyright transfer statement that spells out ownership of the article. This statement must be signed and returned in short order before the manuscript will be published. The corresponding author will receive page proofs, usually electronically, which must be read by the author for accuracy and returned fairly quickly (usually 2-3 days). Many publishers are reluctant to make significant changes in the page proofs, and they may charge for substantial revisions. Thus, the version of the manuscript that is submitted to the journal before the page proofs are generated should be very close to what the author wishes to see in print. Usually at this time publishers will offer the author the option to purchase reprints to allow the author to share the publication with other researchers, co-authors, and colleagues. Some journals will provide a limited number of free reprints or a complimentary copy of the issue of the journal in which the paper appears. The steps in the publication process are summarized in Table 2.

\section{Ethics of Publishing}

"Scholarship (like life) is not always fair or precise." (Thompson 1994)

Table 2 Steps in the Publication Process

\begin{tabular}{ll}
\hline Step & Action \\
\hline 1 & Publish before data are stale. \\
2 & Determine authorship. \\
3 & Choose a journal. \\
4 & Follow the journal's "Instructions for Authors." \\
5 & Submit for peer-review. \\
6 & Editor's decision ${ }^{\text {a }}$ \\
& $\begin{array}{l}\text { a. reject } \\
\text { b. significantly revise and resubmit }\end{array}$ \\
7 & c. accept (possibly with revision) \\
& DO NOT GIVE UP. If appropriate, revise and resubmit; \\
& or else submit to a different journal. \\
9 & Continue until manuscript is accepted for publication. \\
\hline
\end{tabular}

${ }^{\text {a }} \sim 50 \%$ of manuscripts are rejected or require significant revision before being accepted for publication
Manuscript preparation and submission for publication can be complicated by ethical issues. Many authors may not be aware of these ethical conundrums, let alone have a plan for addressing them. Ethics is not a stagnant concept. As research methodologies and research questions evolve, new ethical issues in publishing arise. This section contains a description of several issues broadly relevant to the publishing practice of genetic counselors, particularly as students or recent graduates. However, it is important for genetic counselors-as-authors to keep abreast of ethical issues relevant to their own work.

"Ethics" are principles that govern the behavior of individuals or groups (Merriam-Webster 1974). Ethical codes of conduct exist in order to preserve the integrity of a profession, ensure the public's welfare, and protect scholars. Ethical issues particularly relevant to writing for publication, include: (1) authorship determination, (2) disclosure and conflicts of interest, (3) plagiarism, (4) subject confidentiality, (5) accuracy of information, and (6) publishing in multiple sources.

\section{Authorship Determination}

Consider the following situation: A student conducted an excellent study for her master's thesis project. At the beginning of the project, her supervisor promised her that she would have first authorship on any manuscripts based on the project. However, when the time came to write the paper, the student procrastinated. Finally, after the supervisor repeatedly "nagged" her, she submitted a draft to her, but it was very poorly written. The supervisor decided the only way to salvage the paper was to totally rewrite it herself. Now the supervisor thinks that she deserves to be the first author. Is this ethical? Does it matter if the project was the student's master's thesis rather than a project in which she was voluntarily involved? Are there guidelines that might be implemented in advance to handle this kind of situation?

This complex situation may be all too familiar for many supervisors and students. It raises issues about valuing contributions to the publication process, the power differential between supervisors and students, determining when renegotiation of authorship is warranted, and setting expectations and priorities up front. Whenever manuscripts are authored by more than one individual, order of authorship should be negotiated as early in the process as possible. Only individuals who have actually contributed to the work should be listed as authors. Their order should indicate "...the relative scientific or professional contributions of the individuals involved, regardless of their status" (Shadish 1994) (p. 1096). In the sciences, the first and last authors typically are the individuals that made the greatest contributions to the project (Laflin et al. 2005). Many journals require a listing of each author's contribution to the 
manuscript in order to make sure each person meets the journal's requirements to be listed as an author.

Student authors pose a special situation. Doctoral students usually are the first authors of papers based on their dissertation research (Nguyen and Nguyen 2006). Authorship order is less clear for masters' projects because masters' students may lack sufficient knowledge and skills to conduct a project and prepare a manuscript of publishable quality without considerable input from their supervisor (Shadish 1994). Thompson (1994) recommends that when there is any question as to who made the primary contribution, the student should receive higher authorship. His recommendation helps to protect the person who has less power in the situation. Often students are involved in studies that are not based on their own master's or doctoral research, but rather are connected to an existing research program, such as case examples 1 and 2. In those situations, some authors contend that their involvement should be creative and intellectual in order to warrant authorship; otherwise, student input can be credited in an acknowledgement section (Fine and Kurdek 1993; Holaday and Yost 1995; Thompson 1994).

Negotiating authorship is an important step that should begin in the initial stages of a project. This step usually involves assessing and agreeing upon each person's tasks, contributions, and efforts. The amount of supervision required for an individual's contributions is usually considered as well (Fine and Kurdek 1993). Sometimes renegotiation of authorship order is necessary due to unexpected changes and/or substantial revision of the manuscript. The key is to remember that authorship is negotiated. Questions to consider throughout this negotiation process include: Who had the original idea for the basis of the publication? Who designed and conducted the study that generated the data? Who will write most of the first draft of the paper? Is the study part of someone's research lab? Students should maintain early and on-going communication with their coauthors about their investment of time and efforts and the outcomes of those efforts (Sandler and Russell 2005). However, scholarly contribution is more important than actual time and effort expended when determining authorship. For more information regarding authorship determination, it may be useful to review guidelines for discussing and clarifying authorship order (Gibelman and Gelman 1999) or developing individualized contracts for research collaboration (Stith et al. 1992). These guidelines also may be useful for initiating discussion of authorship as part of the curriculum in genetic counseling training programs.

Take another look at the authorship scenario. At the time of the original negotiation of authorship, it is likely that the supervisor (and other parties) believed the student warranted first authorship due to her creative contributions and time allotted to the study. In most authors' minds, first authorship is equated with substantial contribution to writing the manuscript, usually the first draft, so it is important the student understand this is part of the responsibilities of being first author. Typically students have no experience writing a journal article, and so some procrastination is likely. In this scenario, the authorship dilemma may have been averted by having in place a plan to mentor the student, providing support, and delineating a specific process for writing the first draft of the manuscript.

Manuscripts invariably undergo substantial revision as coauthors and reviewers weigh in, so it is not unusual that the supervisor would revise the student's first draft. This activity does not prima facie warrant a change in authorship order. However, by developing a specific plan to support the student's writing, it may minimize the extent of the supervisor's revisions. It is possible, though, that the student's procrastination and poor writing should initiate a renegotiation of authorship order because the level and nature of her contributions to the work may be changing. The supervisor and student should discuss the reasons for changing authorship order; the supervisor should not unilaterally make this change without discussion. Keep in mind that the bar for changing authorship should be much higher if the paper is based on the student's master's thesis than if it is based on a project in which she was voluntarily involved. It is also important to inform students early in the process that most research is a collaborative effort, requiring time, energy, and sometimes funding, and therefore their collaborators have expectations that their contributions will be rewarded through publication. Developing an a priori policy for renegotiation may often reduce misunderstandings and minimize conflict.

\section{Disclosure and Conflicts of Interest}

Consider the following situation: A student conducted a study to evaluate a new program that her clinic is offering to its patients. She interviewed ten patients who participated in the program about their experience. Nine of these patients were in general agreement about the value of the program, while the 10th patient was quite negative about her experience. The student's impression of this patient is that she is a generally negative person. The student believes that the patient came into the program expecting not to like it. Furthermore, the student is concerned her clinic will lose funding for this program if she reports this patient's responses. The student decides to exclude her data from the paper. Is this decision ethical? Why or why not?

One ethical issue raised in this scenario involves determining when it is appropriate to exclude data points. Data collected from research can be messy, and it is not unusual for some data points to be excluded from analyses. However, there must be an explicit methodology for excluding data points or subjects, and this information usually is reported in the manuscript. Examples for 
exclusions include: missing data (e.g., a participant did not complete a majority of the items on a questionnaire); measurement error (e.g., the recorded measurement of a biological process or part of the anatomy is simply impossible); small sample sizes (e.g., an insufficient number of individuals from a minority group participated in the research resulting in numbers too small for meaningful analysis). In the scenario described above, the rationale provided for excluding the 10th patient's experience is not sufficient to warrant exclusion. Instead, it appears that exclusion of this individual is based on a desire to promote the new program in the student's clinic. In order to eliminate this form of conflict of interest, one could consider involving a clinic outsider in the analysis and interpretation of the data. By including a clinic outsider in the project, editor and reviewer concerns about the integrity of the data, analyses, and conclusions will be allayed.

Most journals provide another "safeguard," by requiring a statement about possible conflicts of interest. A conflict of interest statement requires the author to acknowledge in writing the nature of any circumstances that might bias the process and/or outcome of their work. For example, any project and published report that might result in direct financial gains for an author(s) should be disclosed to a journal's editor and to the readership. Examples of possible conflicts of interest include conducting a study of the effectiveness of a genetic test funded by the company that developed and is marketing the test, or a program evaluation study whose outcome would determine the continuation of the investigators/authors' jobs.

\section{Plagiarism}

Plagiarism is a familiar concept to most people. Everyone generally understands the importance of "giving credit where credit is due." Yet, the National Science Foundation estimates that the prevalence of plagiarism may be as high as $50 \%$ (Roig 2001). Probably many of these incidents are unintentional and/or occur because the authors were unaware of some of the nuances regarding plagiarism. Although there is some variability within and across disciplines about the specific behaviors that constitute plagiarism, there is general agreement about two broad types (Roig 2001): cryptamnesia-an individual thinks their idea is original when it actually was presented by someone else previously; and inappropriate paraphrasing - an individual uses another person's published text without properly citing that use, and/or using their statements with little or no modification. Specific examples of inappropriate paraphrasing include: (1) publishing another person's work as one's own; (2) copying part of another author's paper and claiming it as one's own; (3) copying text from another source without using quotations marks and without citing that source in the text; (4) paraphrasing text from another source without providing an in-text citation; (5) summarizing material from another source without clearly connecting the summary to that source; and (6) using copyrighted materials without author/publisher permission (East 2006; Lester and Lester Jr. 1992).

Additional types of plagiarism include ambiguous use of citations. For instance, an individual includes a citation in a paragraph but does not clearly indicate which content in the paragraph is from the cited work. Another type of plagiarism is self-plagiarism. Self-plagiarism occurs when an individual includes published work of their own for which they do not own the copyright (e.g., reprinting a table from one of their previously published papers); repeating verbatim text from a previously published article. Permission to reprint material from the publisher must be obtained.

Plagiarism is a serious ethical breach which can result in a legal penalty. Strategies for avoiding plagiarism include limiting the use of direct quotes; avoiding the use of secondary sources - it is always better to read and cite an original source when available; and restating ideas in one's own words while providing in-text citation of the work that contains the original ideas (East 2006; Lambie et al. 2008; Lester and Lester Jr. 1992). When in doubt regarding the originality of one's words, it is best to cite the source(s) on which they are based. In this regard, it may help to bear in mind that readers will assume all words in the paper are the author's unless the source(s) are cited.

\section{Subject Confidentiality}

Published papers must be written in a way that no subjects can be recognized by others without their written consent (Gavey and Braun 1997). Given the unique nature of genetics, family members may also need to provide written consent (McCarthy Veach et al. 2001). When possible, identifying information should be removed or disguised (e.g., use of pseudonyms) and data based on multiple subjects should be reported in aggregate (group) form. Institutional review boards (IRBs) play a critical role in assuring protection of subject confidentiality. Many journals require authors to indicate either in the paper or a cover letter that they have obtained institutional review board approval to conduct their animal or human subjects study. In some cases, an ethics board may have been consulted regarding ethical dilemmas reported in a clinical paper and this should be acknowledged in the paper.

Accuracy of Information

Authors are responsible for rigorously checking the accuracy of their facts, data, and conclusions. However, 
despite one's best efforts, substantial errors sometimes are not discovered until after a paper is published. In that case, the corresponding author should contact the journal immediately and ask that an erratum be published. On a related note, authors have a professional responsibility to make data sets reported in published papers available to other professionals. This practice allows for verification of the findings and conclusions, and it also makes possible research replications and extensions of the original study. The length of time for retaining research records depends on institutional policy and sponsor policy, so it is important to be aware of how these policies apply to the research generated by a master's thesis. Often institutional review boards require researchers to state how long they will maintain a data set, and the researchers must adhere to that time frame.

Another accuracy issue concerns modifying and reporting the use of published material (e.g., an interview protocol, psychological instrument, curriculum) without clearly describing the precise nature of the modifications. Interpretation of findings and their comparison to other studies using the "same" instrumentation may be severely compromised when an author fails to report modifications. Further, professional courtesy suggests that permission be sought from the author before changing her or his material. Also, use of published material requires crediting the author(s) of that material by including relevant citations.

\section{Publishing in Multiple Sources}

In the sciences, a manuscript should not be under review by more than one journal at a time. It is, however, acceptable to submit material for presentation at a conference prior to its actual publication in a journal, as the authors in case examples 1 and 3 did. Some conferences publish proceedings, and some journals will not publish work that is already published in a Proceedings unless the two papers differ substantially. When in doubt, it is good practice to contact a journal's editor to determine the journal's policy. Journals typically only publish original work, but on occasion there may be interest in reprinting an article. Reprinting a previously published paper requires written permission from the owner of the publication copyright. As a matter of courtesy, one should also seek the corresponding author's permission, even if the author does not own the copyright.

\section{Examples of Success}

The benefits of sharing knowledge within the medical community and with the public via publication have been delineated. The publication of original work contributes to the advancement of the genetic counseling field overall, and at the individual level, authorship establishes a level of professional credibility, enhancing opportunities for future employability, funding and job satisfaction. The opportunity to develop a genetic counseling master's thesis into a manuscript should therefore not be overlooked. Below are the personal accounts of three recent graduates who successfully transformed their individual master's theses into published manuscripts. These examples were not systematically ascertained, and as such, do not necessarily represent all experiences with trying to publish a master's thesis. These stories provide "first-hand accounts" of the authors' experiences and, while acknowledging the challenges, demonstrate commitment to publishing their own projects throughout their careers. Table 3 contains a list of helpful hints gleaned from these cases.

\section{Case 1: Consider Writing Your Thesis and Journal} Article Concurrently

As a result of personal determination, and above all, strong mentorship, I was able to turn my master's thesis work into a manuscript published in Patient Education and Counseling, titled "Satisfaction with genetic counseling for BRCA1 and BRCA2 mutations among African American women" (Charles et al. 2006). My work was a small component of an existing research project being conducted within a university academically affiliated with my genetic counseling training program. The project was an evaluation of the overall effects of "Culturally Tailored vs. Standard Genetic Counseling Protocol" among African American women.

I started by reviewing previous publications this group of researchers had produced and using these as a guide for my first draft, followed by multiple revisions. Approximately 17 months elapsed between first submission and publication. We submitted the manuscript in its original form in May 2005. We received the reviewers' comments later that summer, and submitted revisions five months later. The article was accepted in that same month, published online five months later and in print seven months after the online version appeared. Shortly after graduating from my program I submitted an abstract of the work to NSGC for presentation at the 2005 Annual

Table 3 Helpful Hints for First Time Authors

1. Learn about the publication process up front and follow directions.

2. Support and mentorship are crucial; learn from and be accepting of constructive criticism.

3. Make the paper a priority; set deadlines and meet them.

4. Communicate with and be accountable to co-authors.

5. Stay positive and keep pushing forward; remember that revisions are part of the process. 
Education Conference, and subsequently learned that it was selected for the NSGC Beth Fine Student Abstract award.

My experience may be unusual because I worked on the manuscript and thesis project concurrently. Composing separate but related documents while still juggling second year genetic counseling student responsibilities was certainly a challenge. Preparing a comprehensive thesis project is a very different task than manuscript composition, the latter of which is more focused and narrow in scope. Challenges posed by this concurrent approach included ensuring that text requirements and deadlines specific to each document were met, as well as incorporating and addressing the reviews of both the training program and peer-reviewers. The main benefits of this approach were that I was still in school and therefore geographically close to my mentors, which facilitated ongoing communication throughout the process, and that the manuscript was under review by a journal before I started my new job.

Factors contributing to the successful publication of this project include mentorship, accountability, and commitment to publication by every author. Supportive, constructively critical, and well published, my mentors had high standards and knew the process. Frankly, I did not want to disappoint them. I found setting deadlines and meeting them, along with the accountability of in-person meetings (as opposed to email), to be effective approaches. Finally, publishing the project was a stated goal of the authors at the initiation of the project. I will not claim that the process was easy, but the goal is certainly attainable and worthwhile.

\section{Case 2: You Need Not Publish Every Thesis Finding-Pick The Most Interesting and Relevant}

As is the case for many graduate students, the first time I attempted to publish was after I completed my thesis. My thesis concerned the development of a minority research recruitment database and was the result of my graduate research on underserved populations.

Following graduation, I started my first job as a genetic counselor in a new city. During the overwhelming process of adjusting to "my new life," my thesis advisor asked me to submit a manuscript to the American Journal of Public Health in response to a call for abstracts on genetics topics. Unfortunately, the deadline was only one week away. I scrambled to cut down my lengthy thesis to a reasonable length and submitted it, knowing that it was not my best work given the time constraint. Needless to say, it was rejected.

I decided that before resubmitting the manuscript to a different journal, I would need to take a different approach to the paper, more or less starting over. While my research results were interesting, they were limited in their application. I decided to publish instead on the success of our research initiative, as other researchers could learn from our process. Since I was changing the focus of the manuscript, I had to do an additional literature search and produce much of the writing from scratch. Most of this work had to be completed in my free time. While it was difficult to stay motivated, working on my manuscript when first starting a job was manageable as my caseload was lightest in the beginning. After several weeks of hard work, I submitted the manuscript to Health Promotion Practice.

About one month later, the editor contacted me and asked me to resubmit my manuscript with revisions. Three different reviewers provided feedback. Initially, it was overwhelming to read through their comments and frustrating, particularly when the reviewers contradicted each other. Despite my frustration, with my co-authors' guidance I forged ahead and resubmitted, only to have the editor and reviewers ask for additional revisions. There were comments from the same three reviewers, however, far fewer in number. Still, I was beginning to think they would never accept the manuscript. I once again called upon my coauthors for guidance and was able to address the reviewers' comments and resubmit the manuscript once again.

This time when I heard from the editor, the manuscript was finally accepted. What started out as a 120 page thesis ended up being published as an eight page paper (Vogel et al. 2007). It took approximately 8 months of writing and revising before the manuscript was finally accepted and an additional year before it came out in print. While the entire process was a true test of patience and determination, it was ultimately worth it. The experience gave me the foundation to carry on my research career and continue to publish successfully.

\section{Case 3: Expectations and Mentorship are Crucial}

I defended my thesis, received my Master's degree, and was about to move back to the Midwest to start my new job as a genetic counselor, but my long "To-Do" list had one remaining item: Publish master's thesis. I started the initial master's thesis process with the expectation from one of my thesis advisors, and now a co-author, that research is not "put down and set aside" until published. I never questioned the process; if I was going to work with this advisor, I would be publishing. I was excited to undertake this challenge and impressed by my thesis advisor's dedication, mentorship, and desire to see our hard work recognized. Nearly two years later, I could proudly say that this expectation, held by all of my thesis advisors and me, was accomplished. The manuscript, published in the $J O G C$, describes qualitative research regarding communication of genetic test results within a family (Blase et al. 2007).

In the beginning, I was unfamiliar with the publication process, but because of the support and guidance of my 
advisors, I began to learn the process, and so the frustrations and uncertainties were minimal. I also had a great working relationship with my co-authors that included communicating regularly and setting and meeting deadlines. After deciding the JOGC was the most appropriate venue for my research, I spent a good deal of time reducing and reformatting the 80 page thesis to a $20-25$ page manuscript to meet the journal's guidelines. Given the page constraints, this process necessitated determining which data to focus on and re-framing some information to appropriately fit the readers of my selected journal. Conversations with my advisors were instrumental in this phase.

There was nothing quick about publishing my master's thesis. I graduated in June 2005, received an email shortly thereafter from one of my advisors about how to begin constructing a first draft of a manuscript, and began working on the manuscript in July 2005. I submitted the manuscript to $J O G C$ in May 2006 and subsequently was informed by the editor that based on the reviews, revisions were required before the manuscript could be considered for publication. In September 2006, after two rounds of revisions, my manuscript was accepted, and by June 2007 it was published in the journal.

Although ultimately I was successful in publishing my master's thesis, the process had its moments of frustration. I remember getting my first round of comments from the reviewers; I thought I was never going to get to the point of publication. My co-authors supported and encouraged me by explaining that revisions are truly part of the process. I was overwhelmed by the reviewers' list of questions and changes after my initial submission, followed by additional reviews and revisions. Not only did I have to figure out how to keep the manuscript a priority in light of my new job, but I had to weed through and address the reviewers' comments, and the suggestions of each co-author. The guidance of my thesis advisors, now co-authors, helped me navigate this process.

I have gained much through this experience. The process has opened doors for me including opportunities to work with other professionals with impressive publishing experiences, as well as speaking and poster presentation opportunities at national conferences. I also have greater confidence about the publishing process. What seemed like such a daunting and impossible task is now an attainable outcome. Although my master's thesis was my most recent publication, the thought of taking on the publication process again is not nearly as intimidating as I once thought.

\section{Conclusion}

Publication of original research, clinical experience, and literature reviews are vital to the growth of the genetic counseling field and to the delivery of genetic counseling services. Publishing also promotes personal growth by counting toward maintenance of ABGC-certification as well as establishing the author as a credible and respected authority both within and outside the genetic counseling field. This professional recognition in turn can lead to employment opportunities, speaking engagements, research funding, and career advancement.

Submitting a manuscript for publication also can be an intellectually challenging, emotionally trying, and timeconsuming task. But similar to life's other difficult tasks, the rewards and satisfaction are commensurately great - to see your name in print, have your work cited by other authors, and know that you have contributed in a meaningful way to the practice and understanding of genetic counseling. Transforming a master's thesis into a journal article is an obvious first step in developing and sustaining a commitment to publishing for our genetic counseling profession. Common themes in the three success experiences include the importance of mentorship and clear expectations for publishing, recognition of the length of the process and concomitant need for perseverance in the face of revisions, awareness of personal and professional benefits in terms of presentations at national meetings, awards, and motivation to continue publishing. Hopefully the information provided in this article will help to de-mystify the publishing process, promote consideration of ethical issues in publishing, and stimulate genetic counseling students and new graduates to embrace a "Publish for Success" philosophy.

Acknowledgments This paper was developed from an Educational Breakout Session (EBS) sponsored by the Jane Engelberg Memorial Fellowship Advisory Group at the 2008 NSGC Annual Education Conference.

Open Access This article is distributed under the terms of the Creative Commons Attribution Noncommercial License (https:// doi.org/creativecommons.org/licenses/by-nc/2.0/), which permits any noncommercial use, distribution, and reproduction in any medium, provided the original author(s) and source are credited.

\section{References}

American Board of Genetic Counseling. 2009. Competencies. http:// www.abgc.net/english/view.asp? $x=1529 \&$ all=true. Accessed October 26, 2009.

Andersen, J., Belmont, J., \& Cho, C. T. (2006). Journal impact factor in the era of expanding literature. Journal of Microbiology, Immunology and Infection, 39, 436-443.

Armstrong, A. W., Idriss, S. Z., Kimball, A. B., \& Bernhard, J. D. (2008). Fate of manuscripts declined by the Journal of the American Academy of Dermatology. Journal of the American Academy of Dermatology, 58, 632-635.

Beeson, D. (1997). Nuance, complexity, and context: qualitative methods in genetic counseling research. Journal of Genetic Counseling, 6, 21-43.

Benose, D. J., Bashari, E., Chaves, J. M., Gaggar, A., Kapoor, N., LaFrance, M., et al. (2007). The ups and downs of peer review. Advances in Physiology Education, 31, 145-152. 
Blase, T., Martinez, A., Grody, W. W., Schimmenti, L., \& Palmer, C. G. S. (2007). Sharing GJB2/GJB6 genetic test information with family members. Journal of Genetic Counseling, 16, 313-324.

Bowen, N. K. (2003). How to write a research article for the Journal of Genetic Counseling. Journal of Genetic Counseling, 12, 5-21.

Boyer, E. L. (1990). Scholarship reconsidered: Priorities of the professoriate. Princeton: Carnegie Foundation for the Advancement of Teaching.

Charles, S., Kessler, L., Stopfer, J. E., Domchek, S., \& Halbert, C. H. (2006). Satisfaction with genetic counseling for BRCA1 and BRCA2 mutations among African American women. Patient Education and Counseling, 63, 196-204.

Chew, M., Villanueva, E. V., \& Van Der Weyden, M. B. (2006). Life and times of the impact factor: retrospective analysis of trends for seven medical journals (1994-2005) and their editors' views. Journal of the Royal Society of Medicine, 100, 142-150.

Clark, H. M., Gamm, J., Huether, C. A., Buncher, C. R., Blough Pfau, R. I., \& Steinberg Warren, N. (2006). Genetic counselors and research: current practices and future directions. American Journal of Medical Genetics Part C (Seminars in Medical Genetics), 142C, 276-283.

Cohen, B. L., Friedman, E., \& Zier, K. (2008). Publications by students doing a year of full-time research: what are realistic expectations? The American Journal of Medicine, 121, 545-548.

Curfman, G. D., Morrissey, S., Annas, G. J., \& Drazen, J. M. (2008). Peer review in the balance. New England Journal of Medicine, $358,2276-2277$.

Driscoll, J., \& Driscoll, A. (2002). Writing an article for publication: an open invitation. Journal of Orthopaedic Nursing, 6, 144-152.

East, J. (2006). The problem of plagiarism in academic culture. International Journal for Educational Integrity, 2, 16-28.

Fine, M. A., \& Kurdek, L. A. (1993). Reflections on determining authorship credit and authorship order on faculty-student collaborations. American Psychologist, 48, 1141-1147.

Garfield, E. (1994). The Thomson Scientific Impact Factor Thomson Reuters (formerly the Institute for Scientific Information (ISI)). http://www.thomsonreuters.com/business_units/scientific/free/ essays/impactfactor/. Accessed 1/24/2009.

Gavey, N., \& Braun, V. (1997). Ethics and the publication of clinical case material. Professional Psychology: Research and Practice, 28, 399-404

Gibelman, M., \& Gelman, S. R. (1999). Who's the author? Ethical issues in publishing. Journal of Social Work Education, 35, 203-213.

Greenwood, D. C. (2007). Reliability of journal impact factor rankings. BMC Medical Research Methodology, 7, 48-53.

Ha, T. C., Tan, S. B., \& Soo, K. C. (2006). The journal impact factor: too much of an impact? Annals of the Academy of Medicine Singapore, 35, 911-916.

Hall, S. A., \& Wilcox, A. J. (2007). The fate of epidemiologic manuscripts: a study of papers submitted to Epidemiology. Epidemiology, 18, 262-265.

Hames, I. (2007). Peer review and manuscript management in scientific journals-Guidelines for good practice. Malden: Blackwell Publishing.
Holaday, M., \& Yost, T. E. (1995). Authorship credit and ethical guidelines. Counseling and Values, 40, 24-31.

Keen, A. (2006). Writing for publication: pressures, barriers, and support strategies. Nurse Education Today, 27, 382-388.

Laflin, M. T., Glover, E. D., \& McDermott, R. J. (2005). Publication ethics: an examination of authorship practices. American Journal of Health Behavior, 29, 579-587.

Lambie, G. W., Sias, S. M., Davis, K. M., Lawson, G., \& Akos, P. (2008). A scholarly writing resource for counselor educators and their students. Journal of Counseling \& Development, 86, 18-25.

Lester, J. D., \& Lester, J. D., Jr. (1992). The research paper handbook. Glenview: Goodyear Books.

Liesegang, T. J., Shaikh, M., \& Crook, J. E. (2007). The outcome of manuscripts submitted to the American Journal of Ophthalmology between 2002 and 2003. American Journal of Ophthalmology, 143, 551-560.

McCarthy Veach, P., Bartels, D. M., \& LeRoy, B. S. (2001). Ethical and professional challenges posed by patients with genetic concerns: A report of focus group discussions with genetic counselors, physicians, and nurses. Journal of Genetic Counseling, 10, 97-120.

McGaghie, W. C., \& Webster, A. (2009). Scholarship, publication, and career advancement in health professions education: AMEE Guide No. 43. Medical Teacher, 31, 574-590.

Merriam-Webster. (1974). The Merriam-Webster dictionary. New York: Pocket Books.

Nguyen, T., \& Nguyen, T. D. (2006). Authorship ethics: issues and suggested guidelines for the helping professions. Counseling and Values, 50, 208-216.

Roig, M. (2001). Plagiarism and paraphrasing criteria of college and university professors. Ethics \& Behavior, 11, 307-323.

Sandler, J. C., \& Russell, B. L. (2005). Faculty-student collaborations: ethics and satisfaction with authorship credit. Ethics \& Behavior, $15,65-80$.

Shadish, W. (1994). APA ethics and student authorship on master's theses. American Psychologist, 49, 1096.

Stith, S. M., Barasch Jester, S., \& Linn, J. L. (1992). Student-faculty collaborative research. Family Relations, 41, 470-474.

The PLoS Medicine Editors. (2006). The impact factor game. PLoS Medicine, 3, e291 doi:210.1371/journal.pmed.0030291.

Thompson, B. (1994). The big picture(s) in deciding authorship order. American Psychologist, 49, 1095-1096.

Thompson, P. J. (2007). How to choose the right journal for your manuscript. Chest, 132, 1073-1076.

United States Copyright Office. (2008). Copyright basics. http://www. copyright.gov/circs/circ1.pdf. Accessed 1/14/2009.

Vogel, K., Murthy, V. S., Dudley, B., Grubs, R. E., Gettig, E., Ford, A., et al. (2007). The use of family health histories to address health disparities in an African-American community. Health Promotion Practice, 8, 350-357.

Wager, E., Parkin, E. C., \& Tamber, P. S. (2006). Are reviewers suggested by authors as good as those chosen by editors? Results of a rater-blinded, retrospective study. BMC Medicine, 30, 13.

Weil, J. (2004). Peer review: an essential step in the publishing process. Journal of Genetic Counseling, 13, 183-187. 